\title{
Machining optimization of composite material by using response surface methodology
}

\author{
Prateek Yadav ${ }^{1 *}$ and Neeraj Kumar ${ }^{2}$ \\ M.Tech Scholar, Department of Mechanical Engineering, Suresh Gyan Vihar University, Jaipur, Rajasthan, India ${ }^{1}$ \\ Professor, Department of Mechanical Engineering, Suresh Gyan Vihar University, Jaipur, Rajasthan, India ${ }^{2}$
}

Received: 21-October-2018; Revised: 12-January-2019; Accepted: 16-January-2019

(C)2019 Prateek Yadav and Neeraj Kumar. This is an open access article distributed under the Creative Commons Attribution (CC BY) License, which permits unrestricted use, distribution, and reproduction in any medium, provided the original work is properly cited.

\begin{abstract}
In this paper, the main objective is an experimental investigation of the various process (input) parameters and performed on a CNC milling machine because it is much better in comparison with other machines in context of accuracy and surface finish. The focus on the properties of the materials along with the cutting condition of the cutting tool and work piece has been made. Design of experiments has been used to study the effect of the main milling parameters such as cutting speed, feed rate and depth of cut on the surface roughness and material removal rate (MRR) of composite material (Al 6063-SiC). After this we use surface roughness and MRR as a response (output) variable in analysis the mathematical model and response surface methodology (RSM) is used for investigation the effect of parameter on surface roughness and MRR. RSM is also used for optimization of these parameters. The effects of three different parameters on the milling process are shown here, which are called cutting speed, depth of cut and feed rate. For this work we conducted 27 experiments from L27 orthogonal array methodology, we use different variables in every single experiment. The value of twenty-seven experiments of surface roughness and material removal rate was achieved by these tests. In this work, this study also serves to determine the contribution of each machining parameters and their interaction for surface roughness and MRR. The results show that the interaction of cutting speed and feed rate is the most relevant parameters of minimizing the surface roughness, feed rate or depth of cut is the influencing factors on maximization of material removal rate.
\end{abstract}

Keywords

Metal matrix composite, CNC milling machine, Process parameter, Surface roughness, MRR, RSM.

\section{Introduction}

Composites are combinations of two materials in which one material is named as the matrix and the other is named as reinforcement. There are different types of composite material based on the type of matrix and reinforcement. We have used metal matrix composite as a composite material. We use Aluminum ( $\mathrm{Al}$ 6063) as base metal and $5 \% \mathrm{SiC}$ as reinforcement for matrix composite. We have prepared composite material by using the stir casting process which includes electric furnace and rotating motor setup for stirring.

It is important to improve system performance and increase process performance without increasing cost. The method used for this purpose is called optimization. Many researchers are working on optimizing processing parameters.

*Author for correspondence

1
Response surface methodology (RSM) is a dynamic and, first of all, an important tool for the design of experiment (DOE), where the relationship between outputs of the process (s) and input decision variables is mapped to achieve the goal of maximizing or minimizing output properties. RSM has been successfully applied for prediction and optimization of cutting parameters.

Chemical composition of the aluminum alloy (Al6063)

We have shown the chemical composition of the Aluminum alloy (Al-6063) in Table 1

Table 1 Chemical composition of the aluminum alloy (Al-6063)

\begin{tabular}{ll}
\hline Elements & Composition (Wt. \%) \\
\hline $\mathrm{Si}$ & $0.2-0.6 \%$ \\
$\mathrm{Fe}$ & $\operatorname{Max} 0.35 \%$ \\
$\mathrm{Cu}$ & $\operatorname{Max} 0.10 \%$ \\
\hline
\end{tabular}




\begin{tabular}{ll}
\hline Elements & Composition (Wt. \%) \\
\hline $\mathrm{Mg}$ & Max $0.10 \%$ \\
$\mathrm{Mn}$ & $0.45-0.90 \%$ \\
Elements & Composition (Wt. \%) \\
$\mathrm{Zn}$ & Max $0.10 \%$ \\
$\mathrm{Cr}$ & Max $0.10 \%$ \\
$\mathrm{Ti}$ & Max $0.10 \%$ \\
Other & $0.05-0.15 \%$ \\
$\mathrm{Al}$ (Remaining) & Max 97.5\% \\
\hline
\end{tabular}

\section{Characteristics of material}

We have shown the characteristics of Aluminum alloy (Al-6063) in Table 2.

Table 2 Characteristics of material

\begin{tabular}{ll}
\hline Melting temperature $(\mathrm{Tm})$ & $615^{\circ} \mathrm{C}$ \\
\hline Density $(\rho)$ & $2.69 \mathrm{~g} / \mathrm{cm} 3$ \\
\hline Young's modulus $(\mathrm{E})$ & $68.3 \mathrm{GPa}$ \\
\hline Tensile strength $(\sigma \mathrm{t})$ & $145-186 \mathrm{MPa}$ \\
\hline Thermal conductivity $(\mathrm{k})$ & $201-218 \mathrm{~W} / \mathrm{m} * \mathrm{~K}$ \\
\hline
\end{tabular}

\section{Literature review}

Patel (2015) [1] had taken process (input) parameters like cutting speed, feed rate, depth of cut, coolant, tool geometry etc. which delivers greater enhancement in productivity, increase the quality of parts of the machine and minimize the production cost.

Malay et al. (2016) [2] took various milling process parameters such as spindle speed, feeding speed and cutting depth were investigated to reveal the impact on surface finish and the material removal rate (MRR). As a result, the feed rate is considered to be the most influential factor for modeling the surface finish according to the authors.

Raju et al. (2015) [3] suggested wire-cut electrical machining process (WEDM) parameters such as pulse on time, pulse off time and peak current to show the most influence factor on smooth surfaces and MRR in aluminum work. The RSM was used as an experimental data optimization.

Ribeiro et al. (2017) [4] suggested four milling parameters such as cutting speed, feed speed, radial depth, and axial depth. These parameters have influenced the roughness of the surface. For this purpose, the L16 orthogonal array, which is part of the Taguchi optimization method, was used to optimize data.

Vishnu et al. [5] discussed the experimental investigation and optimization of the machining parameters of the CNC milling process on the P20 steel work piece. A "box-Behnken" project of RSM was used to collect study data. At this cutting speed, feed rate and cutting depth were used as a process (Input) parameter and MRR, tool wear, surface roughness, cutting forces are considered response (Output) variables. A non-dominant genetic sorting algorithm (NSGA-II) has been proposed by the authors to improve the efficiency of the milling process.

Hashmi et al. (2015) [6] had used, titanium and its alloys have poor thermal conductivity. Author described that in this research only depth of cut effect on composite material by using response surface methodology, technique but by using different cutting speed and feed rate can also be effective response surface methodology.

Vardhan et al. [7] worked on P20 Steel using surface response methodology and Taguchi method to the milling process. They have shown that both techniques offer the same result, but according to few researches, the Taguchi method is not too precise than RSM and RSM provide more accuracy.

Based on the analysis of the literature, we found that the milling machine is better than other machines for accuracy and efficiency. Many parameters of the milling process, such as spindle speed, feed rate, depth of cut, nose radius, cooling agent, tool geometry effect on surface roughness, and MRR. We have chosen only three parameters: spindle speed, feed rate and depth of cut based on the literatures. We have selected RSM for optimizing the experimental results.

\section{Research objectives}

1.RSM is used for the purpose of multi-objective parameters to be optimized.

2.To focus on cutting tool life and accuracy along with surface roughness and MRR and material properties along with cutting condition of cutting tool and workpiece.

Importance of work

1. We optimized multi-objective parameters at a time so we can reduce the time.

2. To increasing production rate by reducing time.

3. The composite material we selected would be used in automotive and aerodynamics.

4. To optimized better composite material. 
2. Experimental setup and methodology Experimental setup

1. Selecting of composite material (Al 6063-SiC) depending upon the application such as to make railway tracks due to their good properties, this composite material used in automotive parts show high tensile strength and flexural module like a wheel, cylinder head and manifolds. Figure 1 shows the composite material.

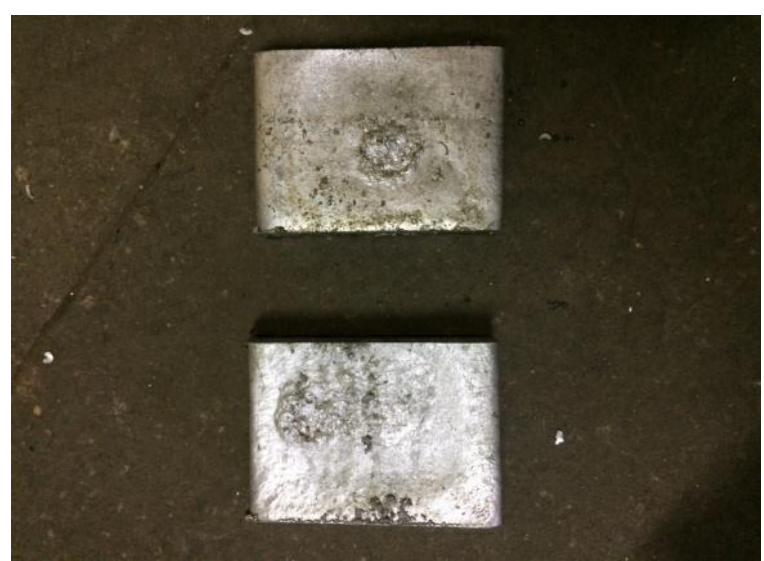

Figure 1 Composite material

2. We have selected the CNC milling machine for machining of the composite material. Figure 2 shows the vertical CNC milling machine.

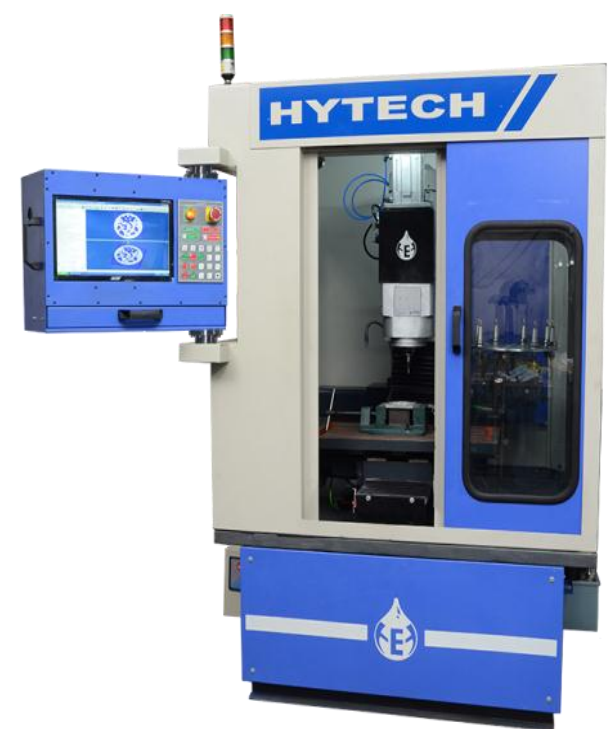

Figure 2 Vertical CNC milling machine

3. We have chosen three different levels of each control factors such as spindle speed, feed rate and depth of cut.

Table 3 shows the input parameter and their levels.

Table 3 Input parameter and their levels

\begin{tabular}{llll}
\hline Control factors (unit) & Level 1 & Level 2 & Level 3 \\
\hline Spindle Speed (rpm) & 2000 & 2200 & 2400 \\
\hline Feed Rate $(\mathrm{mm} / \mathrm{min})$ & 70 & 80 & 90 \\
\hline Depth of Cut $(\mathrm{mm})$ & 0.4 & 0.6 & 0.8 \\
\hline
\end{tabular}

4. We have conducted 27 experiments for the optimization process $[4,7-10]$.

5. For each experiments test is found out and noted, then we calculated the material removal rate with the help of machining time.
6. Surface roughness are measured by the surface roughness measuring tester (SJ-210) and also obtained the graph by each experiment's test of surface roughness. Figure 3 shows the surface roughness measuring tester (SJ-210). 
Prateek Yadav and Neeraj Kumar

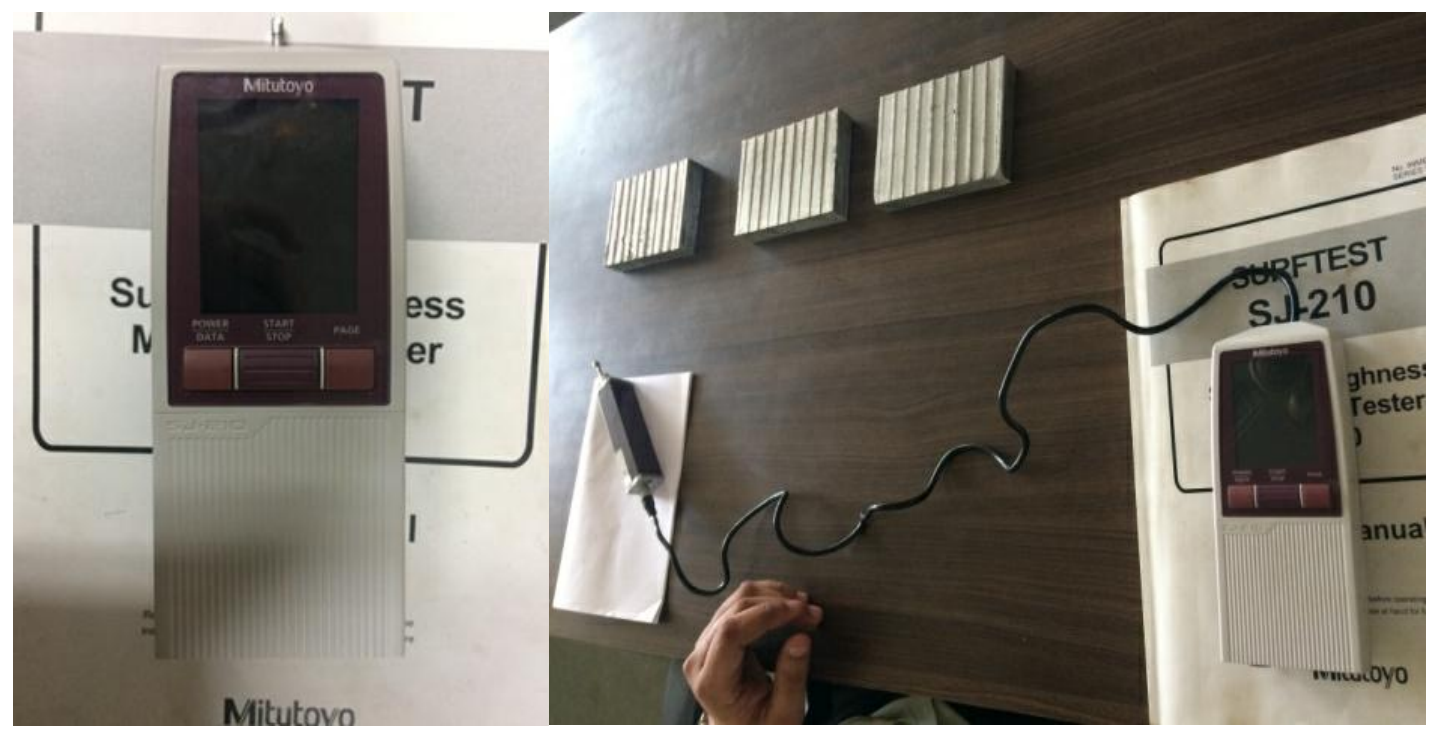

Figure 3 Surface roughness measuring tester (SJ-210)

7. The optimum results, are carried out by the response surface methodology with the help of Minitab software

\section{Methodology}

RSM is used to optimize the obtained result. The investigation is carried out by going through the following phases:

1) Screening

2) Improvement

3) Determination of optimum

i.Screening

Screening is used to determine which factors really influence the outcome; tool: screening designs like fractional factorial.

ii.Improvement
Improvement used to approach optimum by repeated change of factor setting; tool: Box/simplex or steepest ascent approach.

iii.Determination of optimum

Find an optimal setting of factor setting; tool: response surface design like central composite design (CCD) or Box-Behnken + analysis of response surface using Eigen values.

\section{Results and discussion}

Milling machine parameters are optimized for Aluminum composite material using RSM. The influential parameters chosen are cutting speed, depth of cut, feed rate and machining time Surface roughness are determined by the surface roughness tester. Table 4 shows the process control parameter.

Table 4 Process control parameter

\begin{tabular}{|c|c|c|c|c|c|c|}
\hline Experiment No. & $\begin{array}{l}\text { Cutting } \\
\text { (RPM) }\end{array}$ & Speed & $\begin{array}{ll}\text { Feed } & \text { rate } \\
(\mathrm{mm} / \mathrm{min}) & \end{array}$ & 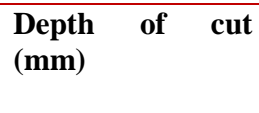 & $\operatorname{MRR}\left(\mathrm{mm}^{3} / \mathrm{min}\right)$ & $\begin{array}{l}\text { Surface } \\
\text { roughness }\left(\mathbf{R}_{\mathrm{a}}\right) \\
(\mu \mathrm{m})\end{array}$ \\
\hline 1 & 2000 & & 70 & 0.4 & 290 & 2.622 \\
\hline 2 & 2000 & & 70 & 0.6 & 414.3953427 & 4.916 \\
\hline 3 & 2000 & & 70 & 0.8 & 566.3140765 & 4.488 \\
\hline 4 & 2000 & & 80 & 0.4 & 315.598549 & 3.274 \\
\hline 5 & 2000 & & 80 & 0.6 & 485.0549791 & 3.645 \\
\hline 6 & 2000 & & 80 & 0.8 & 631.6744819 & 7.450 \\
\hline 7 & 2000 & & 90 & 0.4 & 361.9972261 & 2.113 \\
\hline 8 & 2000 & & 90 & 0.6 & 533.0156569 & 4.003 \\
\hline 9 & 2000 & & 90 & 0.8 & 726.2608696 & 3.998 \\
\hline 10 & 2200 & & 70 & 0.4 & 288.0794702 & 1.711 \\
\hline 11 & 2200 & & 70 & 0.6 & 419.2771084 & 4.052 \\
\hline 12 & 2200 & & 70 & 0.8 & 594.4483986 & 4.259 \\
\hline 13 & 2200 & & 80 & 0.4 & 341.7348609 & 2.107 \\
\hline 14 & 2200 & & 80 & 0.6 & 499.9201915 & 2.478 \\
\hline 15 & 2200 & & 80 & 0.8 & 627.21538 & 8.602 \\
\hline
\end{tabular}


International Journal of Advanced Technology and Engineering Exploration, Vol 6(50)

\begin{tabular}{|c|c|c|c|c|c|}
\hline Experiment No. & $\begin{array}{l}\text { Cutting } \\
\text { (RPM) }\end{array}$ & $\begin{array}{ll}\text { Feed } \\
(\mathrm{mm} / \mathrm{min})\end{array} \quad$ rate & 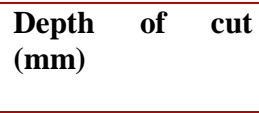 & $\operatorname{MRR}\left(\mathrm{mm}^{3} / \mathrm{min}\right)$ & $\begin{array}{l}\text { Surface } \\
\text { roughness }\left(R_{a}\right) \\
(\mu \mathrm{m})\end{array}$ \\
\hline 16 & 2200 & 90 & 0.4 & 379.3604651 & 2.090 \\
\hline 17 & 2200 & 90 & 0.6 & 528.4292222 & 5.078 \\
\hline 18 & 2200 & 90 & 0.8 & 758.4453324 & 6.263 \\
\hline 19 & 2400 & 70 & 0.4 & 288.7966805 & 1.730 \\
\hline 20 & 2400 & 70 & 0.6 & 426.2384322 & 4.344 \\
\hline 21 & 2400 & 70 & 0.8 & 556.0733974 & 2.670 \\
\hline 22 & 2400 & 80 & 0.4 & 321.2307692 & 4.920 \\
\hline 23 & 2400 & 80 & 0.6 & 462.902749 & 4.422 \\
\hline 24 & 2400 & 80 & 0.8 & 600.0862193 & 2.247 \\
\hline 25 & 2400 & 90 & 0.4 & 390.5723906 & 4.997 \\
\hline 26 & 2400 & 90 & 0.6 & 570.9077652 & 2.660 \\
\hline 27 & 2400 & 90 & 0.8 & 740.6881873 & 2.094 \\
\hline
\end{tabular}

\section{Calculation of MRR}

The material removal rate is obtained using following formulae:

$\mathrm{MRR}=\frac{\mathrm{W} \times \mathrm{D} \times \mathrm{L}}{\mathrm{Tm}}$

Where $\mathrm{W}=$ width of the specimen mild, $\mathrm{d}=10 \mathrm{~mm}, \mathrm{D}=$ Depth of cut

$\mathrm{L}=$ Length of the specimen mild $=87 \mathrm{~mm}$

$\mathrm{T}_{\mathrm{m}}=$ Machining time
In the Figure 4 of main effect plots for roughness show that surface roughness is decreased with increasing the cutting speed and then we found a point in which $R_{a}$ is minimized and then also $R a$ is increasing. $R_{a}$ lies between the $2-3 \mu \mathrm{m}$ with increasing the feed rate. Surface roughness slightly decrease with the depth of cut and then increases the roughness with increasing depth of cut. Table 5 shows the regression coefficients for surface roughness $\left(\mathrm{R}_{\mathrm{a}}\right)$.

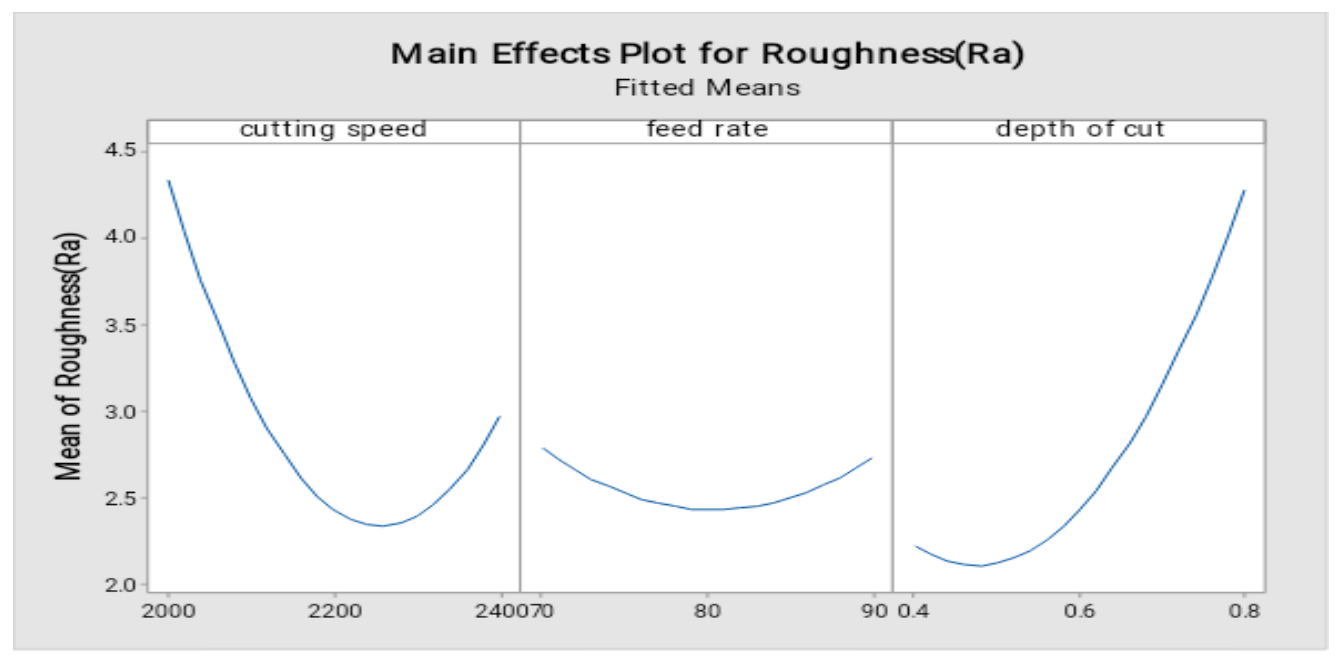

Figure 4 Main effects plot for roughness $\left(\mathrm{R}_{\mathrm{a}}\right)$

Table 5 Regression coefficients for surface roughness $\left(R_{a}\right)$

\begin{tabular}{lllllll}
\hline Term & Effect & Coef & SE Coef & T-Value & P-Value & VIF \\
\hline Constant & & 2.433 & 0.676 & 3.60 & 0.016 & \\
Cutting speed & -1.368 & -0.684 & 0.414 & -1.65 & 0.159 & 1.00 \\
Feed rate & -0.054 & -0.027 & 0.414 & -0.06 & 0.951 & 1.00 \\
Depth of cut & 2.056 & 1.028 & 0.414 & 2.49 & 0.055 & 1.00 \\
Cutting speed*cutting speed & 2.439 & 1.220 & 0.609 & 2.00 & 0.102 & 1.01 \\
Feed rate*feed rate & 0.655 & 0.328 & 0.609 & 0.54 & 0.614 & 1.01 \\
Depth of cut*depth of cut & 1.639 & 0.820 & 0.609 & 1.35 & 0.236 & 1.01 \\
Cutting speed*feed rate & -0.386 & -0.193 & 0.585 & -0.33 & 0.755 & 1.00 \\
Cutting speed*depth of cut & -3.425 & -1.712 & 0.585 & -2.93 & 0.033 & 1.00 \\
Feed rate*depth of cut & 0.812 & 0.406 & 0.585 & 0.69 & 0.518 & 1.00 \\
\hline
\end{tabular}


Prateek Yadav and Neeraj Kumar

Regression equation in uncoded units

Roughness $\left(\mathrm{R}_{\mathrm{a}}\right)=119-0.1042$ cutting speed -0.44 feed rate +58.5 depth of cut +0.000030 cutting speed $\times$ cutting speed +0.00328 feed rate $\times$ feed rate +20.5 depth of cut $\times$ depth of cut 0.000096 cutting speed $\times$ feed rate -0.0428 cutting speed $\times$ depth of cut +0.203 feed rate $\times$ depth of cut

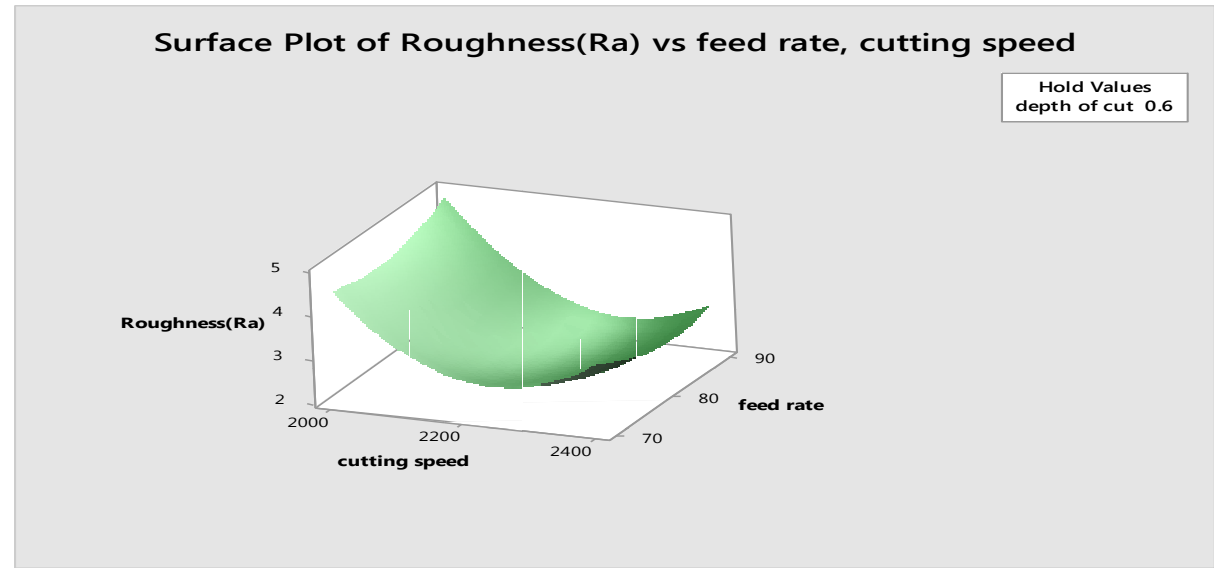

(A)

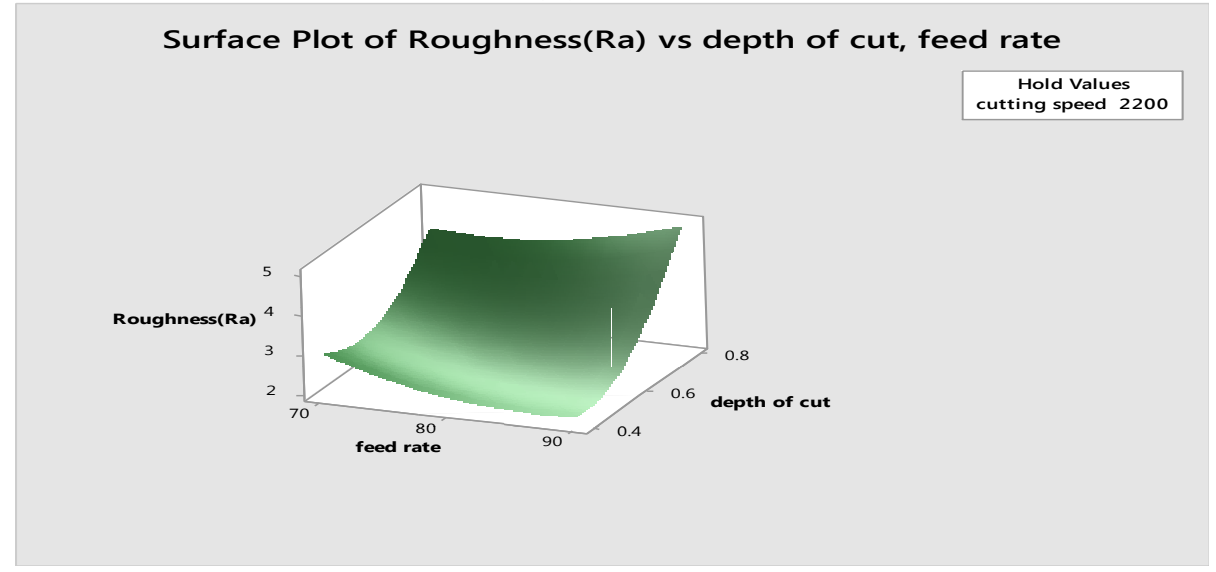

(B)

Surface Plot of Roughness(Ra) vs depth of cut, cutting speed

Hold Values
feed rate 80

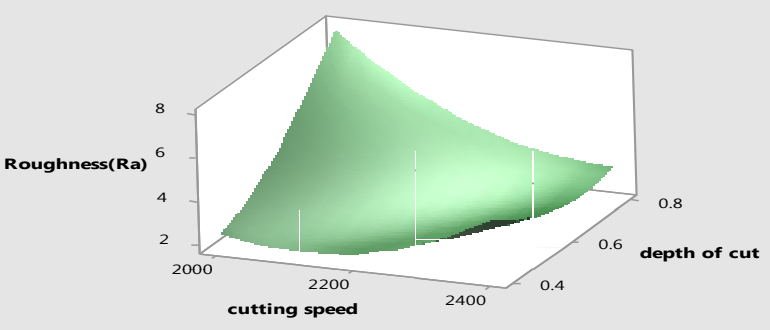

(C)

Figure 5 Response surface of surface roughness vs. cutting speed, feed rate \& depth of cut 
Table 6 Response optimization for surface roughness parameter components

\begin{tabular}{lllllll}
\hline Response & Goal & Lower & Target & Upper & Weight & Importance \\
\hline Roughness $(\mathrm{Ra})$ & Minimum & 1.711 & 7045 & 1 & 1 & \\
\hline
\end{tabular}

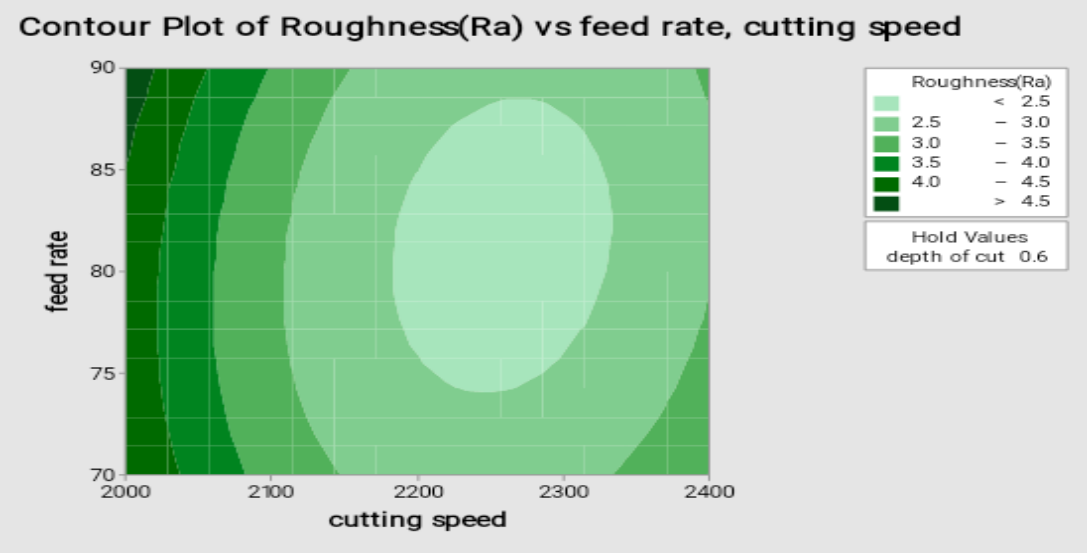

(A)

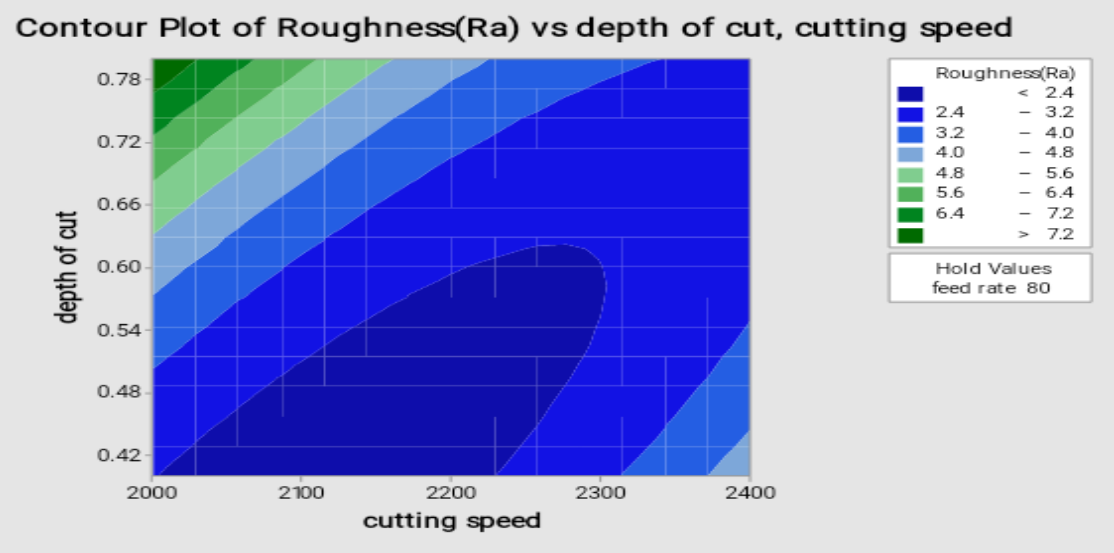

(B)

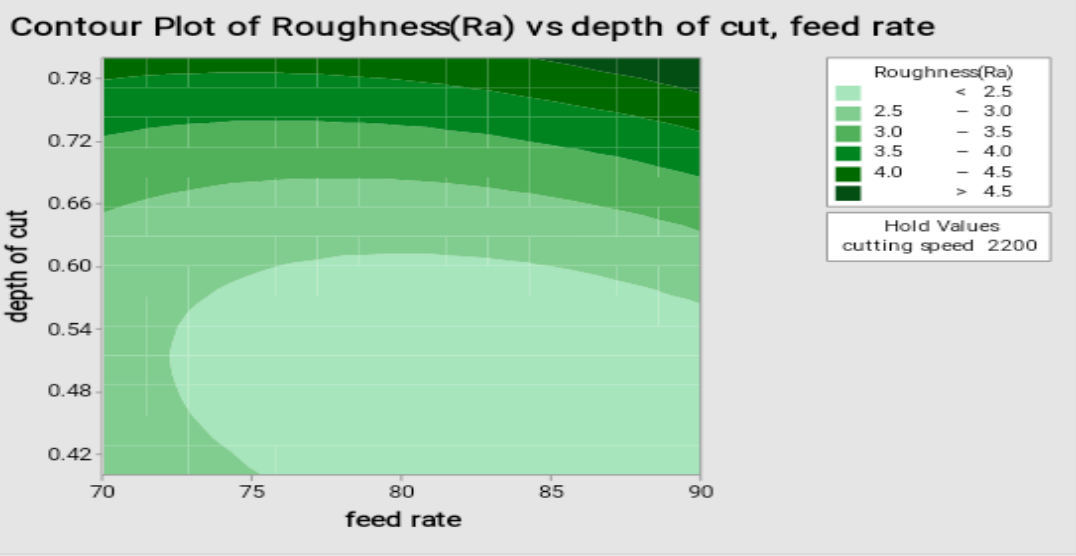

(C)

Figure 6 Contour plot of surface roughness (Ra) vs. Cutting speed, feed rate, \& depth of cut

Figure 5 shows the response surface of surface roughness vs. cutting speed, feed rate $\&$ depth of cut. Table 6 shows the response optimization for surface roughness parameter components. Figure 6 (A) shows that the surface roughness is decreased with increasing cutting speed and increasing feed rate. 
Figure $6(B)$ shows that the surface roughness is decreased with increasing cutting speed and decreasing the depth of cut. Figure $6(C)$ shows that the surface roughness is decreasing with the increasing feed rate and decreasing the depth of cut. Figure 7 shows the interaction plot for roughness (Ra). Figure 8 shows the optimization plot of surface roughness $(\mathrm{Ra})$. Table 7 shows the response optimization solution for $\mathrm{R}_{\mathrm{a}}$. Figure 9 shows the main effect plot of MRR. Table 8 shows the regression coefficients for MRR. Figure 10 shows the interaction plot for MRR. Table 9 shows the response optimization for MRR parameter components. Table 10 shows the response optimization of MRR.

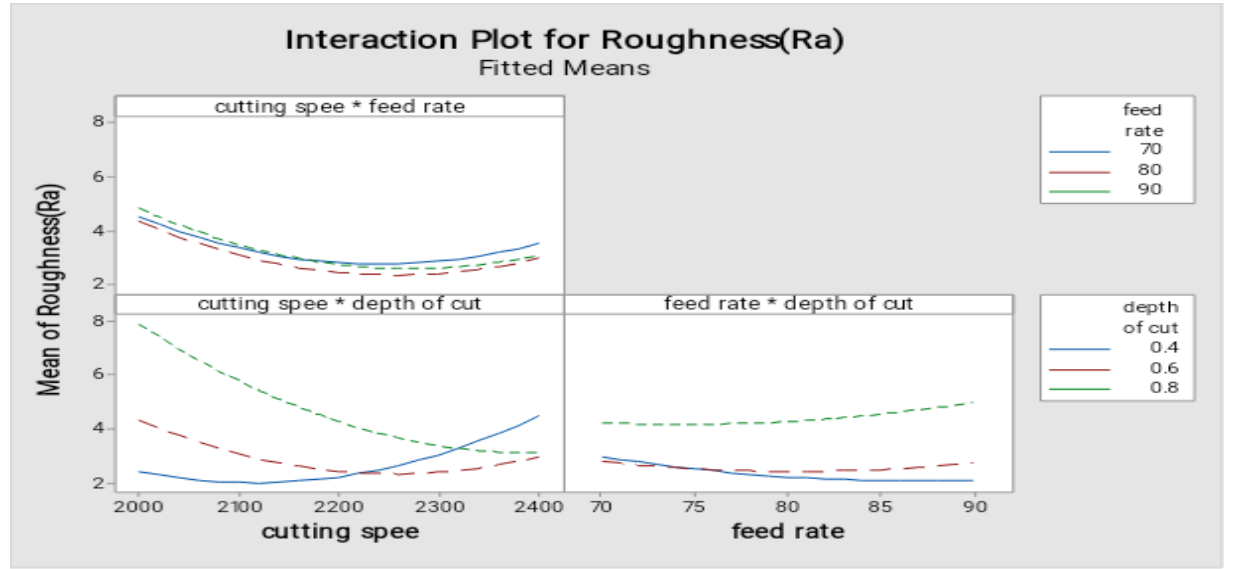

Figure 7 Interaction plot for roughness $\left(\mathrm{R}_{\mathrm{a}}\right)$

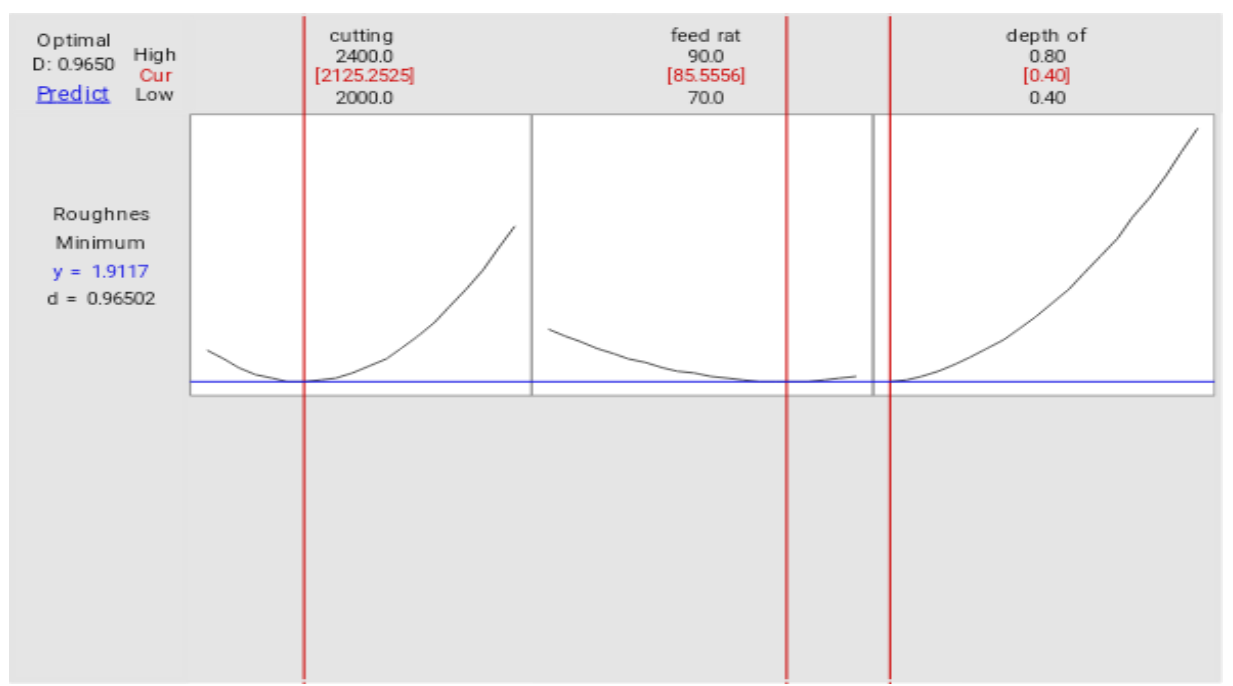

Figure 8 Optimization plot of surface roughness $\left(\mathrm{R}_{\mathrm{a}}\right)$

Table 7 Response optimization solution for $\mathrm{R}_{\mathrm{a}}$

\begin{tabular}{lllll}
\hline Solution & Cutting speed & Feed rate & Depth of cut & Surface roughness (Ra) Fit \\
\hline 1 & 2125.25 & 85.5556 & 0.4 & 1.91172 \\
\hline
\end{tabular}




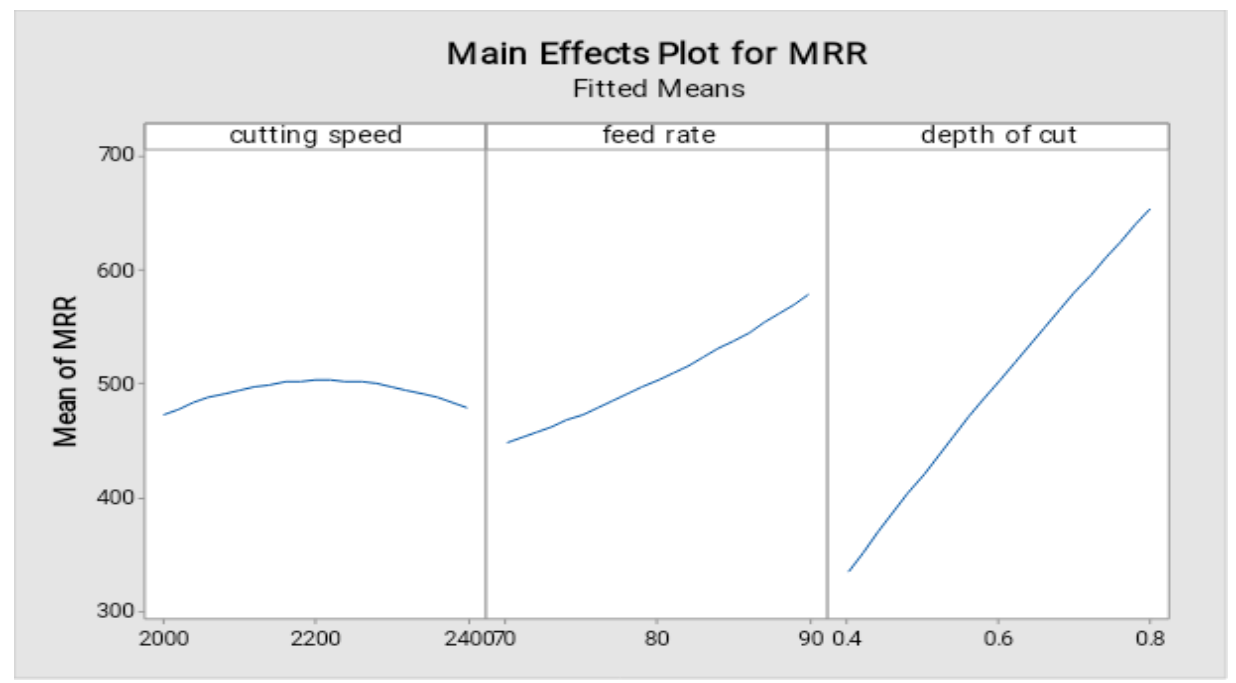

Figure 9 Main effect plot of MRR

Table 8 Regression coefficients for MRR

\begin{tabular}{lllllll}
\hline Term & Effect & Coef SE & Coef & T-Value & P-Value & VIF \\
\hline Constant & & 503.5 & 10.9 & 46.26 & 0.000 & \\
Cutting speed & 5.94 & 2.97 & 6.67 & 0.45 & 0.674 & 1.00 \\
Feed rate & 129.64 & 64.82 & 6.67 & 9.73 & 0.000 & 1.00 \\
Depth of cut & 320.10 & 160.05 & 6.67 & 24.01 & 0.000 & 1.00 \\
Cutting speed*Cutting speed & -55.33 & -27.67 & 9.81 & -2.82 & 0.037 & 1.01 \\
Feed rate*feed rate & 20.54 & 10.27 & 9.81 & 1.05 & 0.343 & 1.01 \\
Depth of cut*depth of cut & -17.44 & -8.72 & 9.81 & -0.89 & 0.415 & 1.01 \\
Cutting speed*feed rate & 13.02 & 6.51 & 9.43 & 0.69 & 0.520 & 1.00 \\
Cutting speed*depth of cut & -18.61 & -9.31 & 9.43 & -0.99 & 0.369 & 1.00 \\
Feed rate*depth of cut & 36.36 & 18.18 & 9.43 & 1.93 & 0.112 & 1.00 \\
\hline
\end{tabular}

Regression Equation in Uncoded Units

$M R R=-2594+2.94$ cutting speed -22.6 feed rate +846 depth of cut -0.000692 cutting speed $\times$ cutting speed +0.1027 feed rate $\times$ feed rate -218 depth of cut $\times$ depth of cut +0.00326 cutting speed $\times$ feed rate -0.233 cutting speed $\times$ depth of cut +9.09 feed rate $\times$ depth of cut

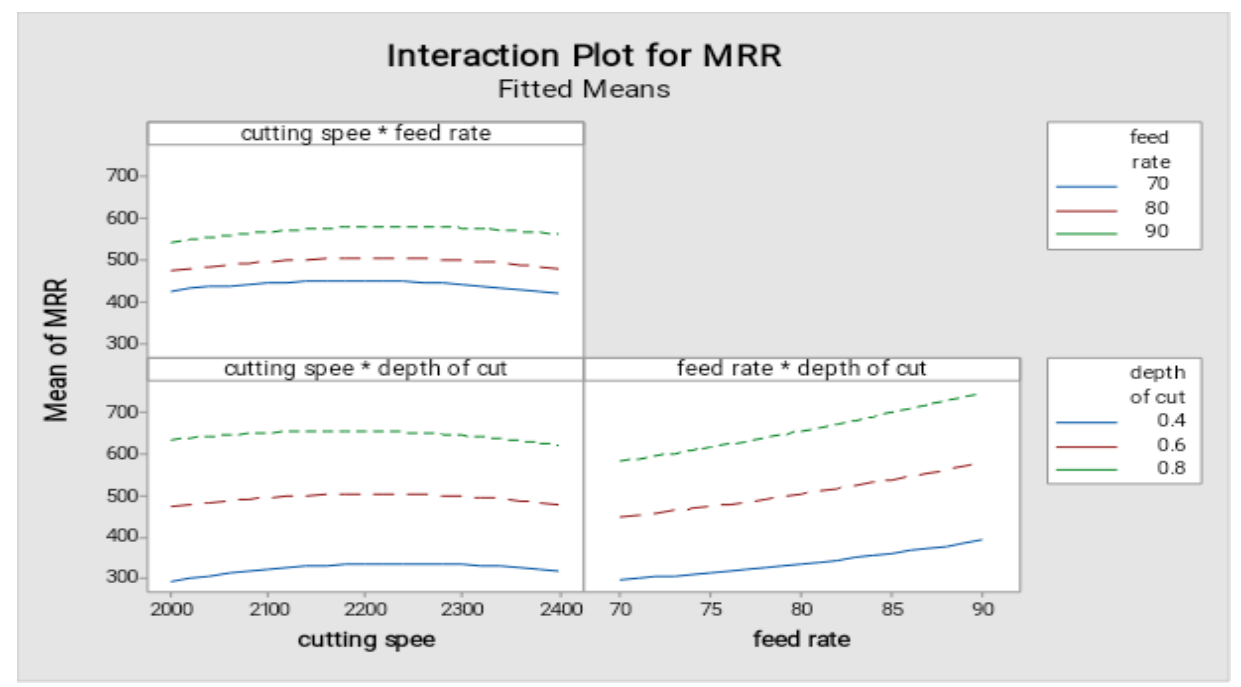

Figure 10 Interaction plot for MRR

9 


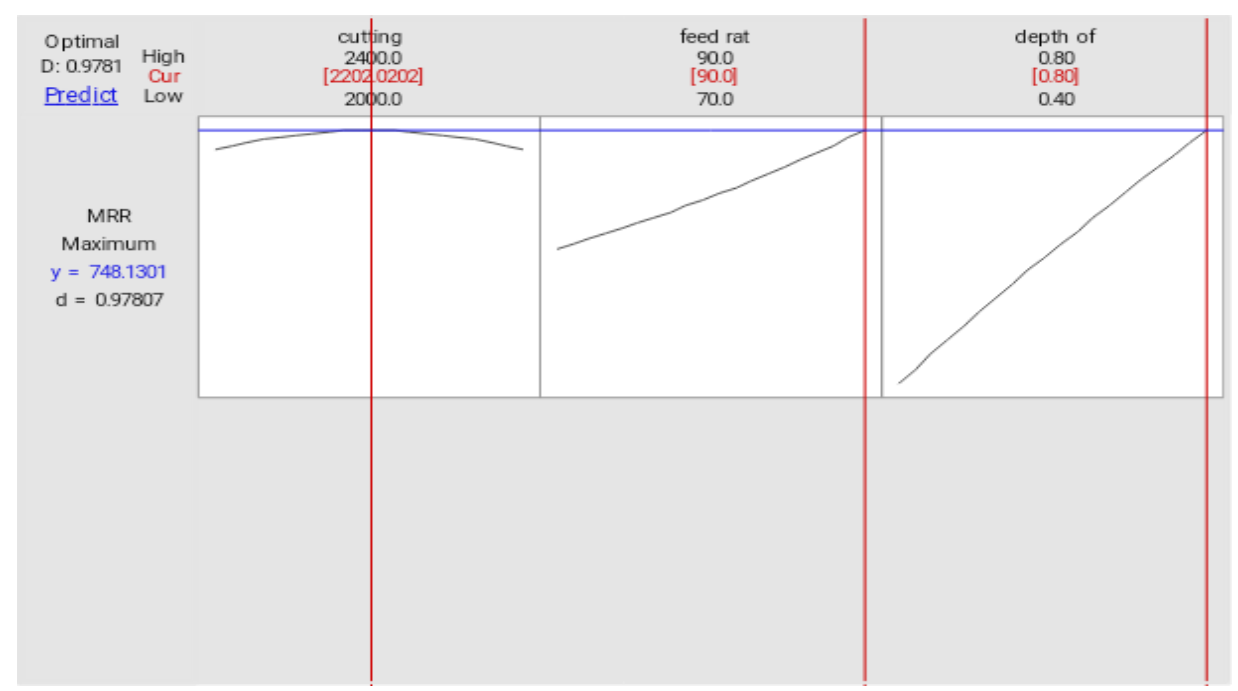

Figure 11 Optimization plot of MRR

Table 9 Response optimization for MRR parameter components

\begin{tabular}{lllllll}
\hline Response & Goal & Lower & Target & Upper & Weight & Importance \\
\hline MRR & Maximum & 288.079 & 758.445 & & 1 & 1 \\
\hline
\end{tabular}

Table 10 Response optimization of MRR

\begin{tabular}{llllll}
\hline Solution & Cutting speed & Feed rate & Depth of cut & MRR FIT & Composite desirability \\
\hline 1 & 2202.02 & 90 & 0.8 & 748.130 & 0.978071 \\
\hline
\end{tabular}

\section{Optimization plot}

A Minitab response optimizer tool shows how different experimental setting affects the predicted response for factorial, response surface and material removal rate. Minitab calculates an optimum solution serves as the starting point of the plot [6].

The optimization plot for surface roughness, as shown in Figure 8, indicated that the minimum.

Surface roughness is $1.911 \mu \mathrm{m}$ obtained at cutting speed $=2125.25 \mathrm{RPM}$, feed rate $=85.56 \mathrm{~mm} / \mathrm{min}$, and depth of cut $=0.4 \mathrm{~mm}$.

The optimization plot for MRR as shown in Figure 11 shows that the maximum MRR is 748.13 $\mathrm{mm}^{3} / \mathrm{min}$ obtained when cutting speed $=2202.02 \mathrm{rpm}$, feed rate $=90 \mathrm{~mm} / \mathrm{min} \&$ depth of cut $=0.8 \mathrm{~mm}$.

\section{Conclusion and future scope}

In this document, CNC milling parameters were determined for multiple performance characteristics (surface roughness and MRR) by response surface modeling and optimization based on convenience. Based on the results, the following conclusions can be drawn:
1. RSM is used for the modeling of CNC milling parameters in the machining of $\mathrm{Al} 6063 / \mathrm{SiC}$ composites. The results indicate that the models are effective in predicting multiple responses in the milling compound.

2. The optimization of multiple responses was performed using the response surface methodology. The optimum solution actually reduces the response in the milling of composite. The optimal solution that was obtained was almost optimal and can be improved considering several variables and levels.

3. The optimization result shows that it is necessary to combine the cutting speed, feed rate and cutting depth to minimize surface roughness and maximize the material removal rate.

In the current research the milling machine parameters were optimized by RSM technique.

The following can be considered as the scope for future work:

1. Research can be based on optimizing various machining parameters for different composite material. 
2. Research can also be carried on a machine other than milling machine. A better optimization technique may be employed.

3. The results of various optimization techniques for the same material and machine can be compared and studied.

4. A comparative study can be carried out for optimizing machining parameter for different metals or alloys and composite materials.

\section{Acknowledgment}

None.

\section{Conflicts of interest}

The authors have no conflicts of interest to declare.

\section{References}

[1] Patel MT. Optimization of milling process parametersa review. International Journal of Advanced Research in Engineering and Applied Sciences. 2015; 4(9):2437.

[2] Malay, Gupta K, Gangwar J, Khan H N, Sharma N P, Mandal A, et al. Optimization of process parameters of CNC milling. International Journal of Advance Research and Innovation. 2016; 3(4):59-63.

[3] Raju BN, Roy MR, Rajesh S, Ramji K. Optimization of machining parameters for cutting AMMC's on wire cut EDM using RSM. International Journal of Engineering Trends and Technology. 2015; 23(2):829.

[4] Ribeiro JE, Cesar MB, Lopes H. Optimization of machining parameters to improve the surface quality. Procedia Structural Integrity. 2017; 5:355-62.

[5] Mukkoti VV, Sankaraiah G, Yohan M. Optimization of process parameters in CNC milling for machining P20 steel using NSGA-II. IOSR Journal of Mechanical and Civil Engineering. 2017; 14(3):57-63.

[6] Hashmi KH, Zakria G, Raza MB, Khalil S. Optimization of process parameters for high speed machining of Ti-6Al-4V using response surface methodology. The International Journal of Advanced Manufacturing Technology. 2016; 85(5-8):1847-56.
[7] Vardhan MV, Sankaraiah G, Yohan M, Rao HJ. Optimization of parameters in CNC milling of P20 steel using response surface methodology and Taguchi method. Materials Today: Proceedings. 2017; 4(8):9163-9.

[8] Rudrapati R, Sahoo P, Bandyopadhyay A. Optimization of process parameters in $\mathrm{CNC}$ turning of aluminium alloy using hybrid RSM cum TLBO approach. In IOP conference series: materials science and engineering 2016 (pp. 1-13) IOP Publishing.

[9] Singh B, Khanna R, Goyal K, Kumar P. Optimization of input process parameters in CNC milling machine of EN24 steel. International Journal of Research in Mechanical Engineering and Technology. 2013.

[10] Yazdi MS, Khorram A. Modeling and optimization of milling processby using RSM and ANN methods. International Journal of Engineering and Technology. 2010; 2(5):474-80.

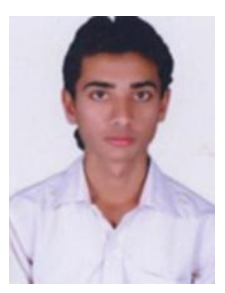

Prateek Yadav is pursuing Master's degree in Manufacturing and Industrial Engineering from Suresh Gyan Vihar University, Jaipur. He graduated with his Bachelor of Technology in Mechanical Engineering at the Institute of Suresh Gyan Vihar University, Jaipur in 2016.

Email: prateek0310yadav@gmail.com

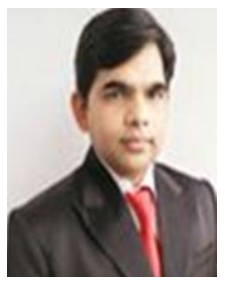

Dr. Neeraj Kumar holds Ph.D (Mechanical), M.Tech (Manufacturing System Engineering) \& B.E (Mechanical) with 11 years' of experience inclusive of 10 years as Engineering Teaching Faculty. $\mathrm{He}$ Published 4 books and 50 research papers. Presently Associate with Suresh Gyan Vihar University, Jaipur as a Head of Mechanical Department and Professor. 